\title{
Lymphatic Vasculature Requires Estrogen Receptor- $\alpha$ Signaling to Protect From Lymphedema
}

\author{
Florent Morfoisse,* Florence Tatin,* Benoit Chaput, Nicole Therville, Charlotte Vaysse, \\ Raphael Métivier, Julie Malloizel-Delaunay, Francoise Pujol, Anne-Claire Godet, Fabienne De Toni, \\ Frederic Boudou, Katia Grenier, David Dubuc, Eric Lacazette, Anne-Catherine Prats, \\ Julie Guillermet-Guibert, Francoise Lenfant, Barbara Garmy-Susini
}

Objective-Estrogens exert beneficial effect on the blood vascular system. However, their role on the lymphatic system has been poorly investigated. We studied the protective effect of the $17 \beta$ estradiol—-the most potent endogenous estrogen -in lymphedema - a lymphatic dysfunction, which results in a massive fluid and fat accumulation in the limb.

Approach and Results - Screening of DNA motifs able to mobilize ERs (estrogen receptors) and quantitative real-time polymerase chain reaction analysis revealed that estradiol promotes transcriptional activation of lymphangiogenesis-related gene expression including VEGF (vascular endothelial growth factor)-D, VEGFR (VEGF receptor)-3, lyve-1, and HASs (hyaluronan synthases). Using an original model of secondary lymphedema, we observed a protective effect of estradiol on lymphedema by reducing dermal backflow—a representative feature of the pathology. Blocking ER $\alpha$ by tamoxifen - the selective estrogen modulator-led to a remodeling of the lymphatic network associated with a strong lymphatic leakage. Moreover, the protection of lymphedema by estradiol treatment was abrogated by the endothelial deletion of the receptor $\mathrm{ER} \alpha$ in Tie2-Cre; ER $\alpha^{\text {loxlox }}$ mice, which exhibit dilated lymphatic vessels. This remodeling correlated with a decrease in lymphangiogenic gene expression. In vitro, blocking ER $\alpha$ by tamoxifen in lymphatic endothelial cells decreased cell-cell junctions, inhibited migration and sprouting, and resulted in an inhibition of Erk but not of Akt phosphorylation.

Conclusions-Estradiol protection from developing lymphedema is mediated by an activation of its receptor ER $\alpha$ and is antagonized by tamoxifen. These findings reveal a new facet of the estrogen influence in the management of the lymphatic system and provide more evidence that secondary lymphedema is worsened by hormone therapy.

Visual Overview-An online visual overview is available for this article. (Arterioscler Thromb Vasc Biol. 2018;38: 1346-1357. DOI: 10.1161/ATVBAHA.118.310997.)

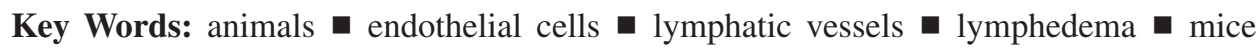

$\mathrm{T}$ he hormonal control of lymphatic tissue is an important issue for decades but remains largely unexplored. The role of estrogens, particularly the $17 \beta$-estradiol, is clearly established for development of sexual characters, reproduction, and in many physiological processes, including cardiovascular function. ${ }^{1-4}$ The biological effects of estradiol are initiated after binding to the ERs (estrogen receptors) $\alpha$ and $\beta$, belonging to a nuclear receptor subfamily of ligand-inducible transcription factors. ${ }^{5,6}$ The endothelial function of estradiol is mediated by the receptor ER $\alpha .{ }^{7,8}$ Estradiol induces ER dimerization to promote gene expression regulation by binding directly to DNA sequences called estrogen response elements (EREs) ${ }^{9}$ or indirectly through protein-protein interactions with other DNA-binding transcription factors. ${ }^{10,11} \mathrm{ER} \alpha$ has also been localized at the plasma membrane and mediates nongenomic signaling pathway leading to ERK and Akt phosphorylation. ${ }^{12,13}$
Despite an abundant literature demonstrating the beneficial effect of estradiol on blood vessels, nothing is known about its effects on lymphatic endothelium. Estradiol influences subcutaneous tissue and morphology by controlling hyaluronic acid synthesis ${ }^{14}$ — a major extracellular matrix ligand for the lymphatic endothelial cell (LEC) receptor Lyve- $1^{15}$ - suggesting an indirect effect on lymphatic homeostasis. A defect in estrogens has been associated with cardiovascular diseases because women develop 2 to $3 \times$ less cardiovascular diseases before menopause. ${ }^{16}$ Importantly, hormonal status has been associated with lymphatic disorders, such as lymphedema-a disorder of the lymphatic vascular system characterized by impaired lymphatic return and swelling of the extremities and an accumulation of fat and fibrosis in the arm or the leg. ${ }^{17}$ Whereas primary lymphedema-a rare disease-is sex linked with an average ratio of 1 male for 3 females,

Received on: October 31, 2017; final version accepted on: March 19, 2018.

From the Institute of Metabolic and Cardiovascular Diseases of Toulouse, Université de Toulouse (F.M., F.T., F.P., A.C.G., F.D.T., F.B., E.L., A.C.P., F.L., B.G.-S.) and Unité Mixte de Recherche 1037-Centre de Recherche en Cancérologie de Toulouse (N.T., J.G.-G.), Inserm, Université Paul Sabatier, France; Department of Plastic Surgery (B.C.) and Department of Vascular Medicine (J.M.-D.), Centre Hospitalo-Universitaire Rangueil, Toulouse, France; Department of Gynecology Surgery, IUCT-Oncopole, Toulouse, France (C.V.); Unité Mixte de Recherche Centre National de la Recherche Scientifique 6290, Rennes, France (R.M.); and Centre National de la Recherche Scientifique, Laboratoire d'analyse et d'architecture des systèmes, Toulouse, France (K.G., D.D.).

*These authors contributed equally to this article.

The online-only Data Supplement is available with this article at http://atvb.ahajournals.org/lookup/suppl/doi:10.1161/ATVBAHA.118.310997/-/DC1. Correspondence to B. Garmy-Susini, PhD, INSERM U1048, 1 Ave Jean Poulhès, 31432 Toulouse, France. E-mail barbara.garmy-susini@inserm.fr (C) 2018 American Heart Association, Inc. 


\begin{tabular}{|ll|}
\hline \multicolumn{2}{|l|}{ Nonstandard Abbreviations and Acronyms } \\
\hline ER & estrogen receptor \\
ERE & estrogen response element \\
HAS & hyaluronan synthase \\
HDLEC & human dermal lymphatic endothelial cell \\
LEC & lymphatic endothelial cell \\
OVX & ovariectomized \\
PCR & polymerase chain reaction \\
VEGF & vascular endothelial growth factor \\
VEGFR & vascular endothelial growth factor receptor \\
\hline
\end{tabular}

the role of hormones, in particular estrogens, has never been investigated in secondary lymphedema. ${ }^{18,19}$ Secondary lymphedema occurs after cancer treatment or filarial infection. ${ }^{20-22}$ Although it is a common disabling disease causing significant morbidity, treatment of lymphedema remains limited and largely ineffective, mainly consisting in compression bandaging. In Western countries, $10 \%$ to $15 \%$ of women develop lymphedema after breast cancer treatment. ${ }^{23-25}$ Despite the recent improvement of surgical technics, lymphedema remains a frequent concern of cancer surgery. An issue to study secondary lymphedema has been hampered by the lack of experimental model. However, mouseinduced lymphedema has been described after a circumferential incision made through the dermis close to the tail base to sever the dermal lymphatic vessels. ${ }^{26}$ In parallel, a primary lymphedema has been generated by heterozygous inactivating missense mutations of the gene encoding VEGF (vascular endothelial growth factor)-C/D receptor (VEGFR [VEGF receptor]-3). ${ }^{27}$ In this study, we developed a novel model of secondary lymphedema mimicking human pathogenesis of secondary lymphedema to explore the effect of estradiol on lymphatic endothelium. We found that $\mathrm{ER} \alpha$ directly regulates lymphangiogenic genes to promote LEC migration and sprouting. We determined that blocking ER $\alpha$ using a selective estrogen modulator, such as the tamoxifen, has a detrimental effect on lymphatic drainage and function, increasing the risk of developing secondary lymphedema. Importantly, the endothelial invalidation of Ero in Tie2-Cre; ER $\alpha^{\text {lox/lox }}$ mice showed enlarged and abnormal lymphatic vessels associated with a loss of estradiol-protective effect on lymphedema. Mechanistically, estradiol targeted both gene expression and cell morphology to activate LEC Erk signaling suggesting that both nuclear and membrane $\mathrm{ER} \alpha$ are expressed in LEC.

Altogether, this study suggests the crucial role of estradiol-the most predominant estrogen-in restoring a functional lymphatic endothelium after healing. Our work not only deciphers the mechanism of the role of estradiol on the LEC but involves medical aspects of quality of life of patients with breast cancer because no treatment is currently proposed to women who developed secondary lymphedema.

\section{Materials and Methods}

The authors declare that all supporting data are available within the article.

\section{Reagents}

Rabbit anti-mouse lyve-1 antibody (RDI-103PA50) was from Research Diagnostics, Inc (Concord, MA). Donkey anti-rabbit and rat IgGs conjugated with alexa 488, 594 were from TebuBio (TebuBio,
Le Perray en Yvelines, France). Anti-pSer473Akt, anti-Akt, and anti-pThr202/Tyr204 Erk1/2 are from Cell Signaling Technology. Anti-phalloidin was from Cytoskeleton (acti-stain phalloidin 488, cat PHDG1). Anti-phospho-VEGFR-3 is from Cell Applications, Inc. Masson trichrome and Red oil were from Sigma-Aldrich, France. Alcyan Blue was from Sigma-Aldrich. Matrigel was from BD. Tamoxifen and $17 \beta$ estradiol are from Sigma-Aldrich. MEK inhibitor (PD098059) was from Invivogen.

\section{Mouse Model of Lymphedema}

Animal experiments were conducted in accordance with recommendations of the European Convention for the Protection of Vertebrate Animals Used for Experimentation. All animal experiments were performed according to the INSERM IACUC guidelines for laboratory animal husbandry and have been approved by the local branch Inserm Rangueil-Purpan of the Midi-Pyrénées ethics committee. Mice model will be restricted to female mice because this article is focusing on the effect of estrogen and women breast cancer-associated hormone therapy. Lymphedema was established in the left upper limbs of 6-week-old C57B1/6 female mice. Bilateral ovariectomy were performed on 4-week-old C57B1/6 followed by implantation of 60-day time release $17 \beta$ estradiol pellets $(0.1 \mathrm{mg}$ estradiol, releasing $80 \mathrm{~g} / \mathrm{kg}$ per day, Innovative Research of America, FL) or tamoxifen (5 mg pellet Innovative Research of America, FL) subcutaneously into the back of the animals using a sterile trocar or with placebo-releasing pellets. Two weeks after ovariectomy, lymphedema surgical procedure is performed. A partial mastectomy of the second mammary gland is associated with axillary and brachial lymphadenectomy. Limb size was measured in the axillary and distal regions using caliper. Mice sustained reproducible edema for a period of $>2$ weeks.

\section{Quantitative Real-Time Polymerase Chain Reaction}

Total cellular RNA was isolated from mouse skin and subcutaneous adipose tissue using a TissueLyser (Ultrathurax; IKA, Staufen, Germany) in Trizol solution according to manufacturer instructions. A total of $1 \mu \mathrm{g}$ RNA was used to synthesize cDNA using HighCapacity cDNA Reverse Transcription Kit (Applied Biosystems, Villebon-sur-Yvette, France). The expression of human and murine VEGF-C, VEGF-D, VEGFR-3, Lyve-1, HAS1, HAS2, and HAS3 was investigated by SYBR Green real-time reverse-transcribed polymerase chain reaction (PCR) using the AB 7900 HT Fast Real-Time PCR System (Applied Biosystems, Villebon-sur-Yvette, France). Each reaction was run with $18 \mathrm{~S}$ as a reference gene, and all data were normalized based on the expression levels of $18 \mathrm{~S}$.

\section{Primers}

VEGF-C (F): 5'-AGGGAAGAAGTTCCACCATCA-3'; VEGF-C (R): 5'-ACAATGCTTCAGTCGATTCGC-3'; VEGF-D (F): 5' - CCT ATTGACATGCTGTGGGAT-3'; VEGF-D (R): 5'-GTGGGTTCCTGG AGGTAAGAG-3'; VEGFR-3 (F): 5'-TTTATGTCCCACCCCC ACTAC-3'; VEGFR-3 (R): 5'-GGCTGAGCTACAAGGCAATCG-3'; HAS1 (F): 5'-TAACTACGTCCCCGTGTTGC-3'; HAS1 (R): 5'-CAGCAAGGTGGTAGGCTTCA-3'; HAS2 (F): 5'- CACTGC TGCTGGGACTTGAA-3'; HAS2 (R): $5^{\prime}$ - AGACATCATCCC ACCGTCCT-3'; HAS3 (F): 5' - AAGGACCGATCTGAAACGCA-3'; HAS3 (R): 5' - TACAAGCCCATCTGCCCAAT-3'; 18S (F): 5'-CAACT AAGAACGGCCATGCA-3'; 18S (R): 5'-AGCCTGCGGCTTAA TTTGAC-3'; Lyve-1 (F): 5'-CAGCACACTAGCCTGGTGTTA-3'; Lyve-1 (R): 5'-CGCCCATGATTCTGCATGTAGA-3'. sh RNA ERa (TRCN0000003300) is from Sigma-Aldrich.

\section{LEC Isolation}

Mice were injected twice with a 2-week interval with incomplete Freund adjuvant to develop lymphangioma on diaphragm and liver surface. After 4 weeks, tumors are harvested before digestion in liberase TM enzyme (Roche) for 10 minutes at $37^{\circ} \mathrm{C}$. Supernatants were filtered through a $100-\mu \mathrm{m}$ cell strainer into a $50-\mathrm{mL}$ tube on ice. After lysis of erythrocytes (RBC lysis buffer; eBioscience), cells were filtered through a $40-\mu \mathrm{m}$ cell strainer. Cells were incubated with Fc-blocking antibody CD16/CD32 for 30 minutes and then stained for the following antibodies on ice for 30 minutes: APC-CD31, 
CD45-BB515 (BD Pharmingen), and LYVE-1-PE (RD Systems). Dead cells were excluded from analysis using live dead violet staining (Invitrogen).

LEC isolation: Lymphangioma from Tie2-cre; ER $\alpha^{\text {lox/lox }}$ mice and control littermates were pooled to isolate LEC. LECs were then dissociated as described previously using LYVE-1-PE (RD Systems:223322), CD45-BB515 (BD Pharmingen:564590), and CD31-APC (BD Pharmingen:561814) antibody. LECs (LYVE-1+ CD31+ CD45-) were separated using a BD influx cell sorter.

\section{Flow Cytometry Analysis}

Lymph nodes from normal, OVX (ovariectomized), estradiol, and tamoxifen-treated mice were removed at the time of the lymphedema surgery and compared with lymph nodes from the same mice, which developed lymphedema 4 weeks after surgery. Lymph nodes were dissociated with liberase TM enzyme (Roche) for 10 minutes at $37^{\circ} \mathrm{C}$. Supernatants were filtered through a $100-\mu \mathrm{m}$ cell strainer into a $50-\mathrm{mL}$ tube on ice. After lysis of erythrocytes (RBC lysis buffer; eBioscience), cells were filtered through a $40-\mu \mathrm{m}$ cell strainer. Cells were incubated with Fc-blocking antibody CD16/CD32 (Affymetrix, eBioscience) for 30 minutes and then stained for the following antibodies on ice for 30 minutes: BB515-CD45 (BD Pharmingen), CD11b-PEvio770 (Miltenyi Biotec 130-109-365), CD206 PerCP/ Cy5.5 (BioLegend, 141715), and F4/80 (BioLegend, clone BM8). Dead cells were excluded from analysis using live dead violet staining (Invitrogen). Experiment controls were performed using the appropriate control antibodies (APC-IgG2a, 400511; BB515IgG2b, 564421; REA control PEvio770, 130-104-616, PerCP/ Cy5.5,400531). Flow cytometry was performed using a BD Fortessa cytometer and FACSDiva software analysis.

\section{Intralymphatic FITC-Dextran Injections}

Mice were anesthetized with a subcutaneous injection of ketamine (100 $\mathrm{mg} / \mathrm{kg}$ ) and xylazine $(10 \mathrm{mg} / \mathrm{kg})$, and the integrity of the lymphatic vasculature of the skin was examined by fluorescence microlymphangiography. A fluorescently labeled macromolecule $(70000 \mathrm{kDa}$ fluorescein isothiocyanate-dextran-conjugated dextran, $2 \mathrm{mg} / \mathrm{mL}$; Sigma-Aldrich, France) was injected into the footpad of the edematous and control leg. Because of its large size, the tracer was taken up by the lymphatics but was excluded from the blood vasculature. As the lymphatic vessels transported fluorescent tracer, it was clearly visible within dermal lymphatic capillaries and collecting vessels, thus providing a clear visualization of lymphatic functionality. The integrity of the lymphatic vasculature was monitored with a Leica Dmi8 (Leica Microsystems, France). Score quantification of the leakage has been established: score 1 corresponds to no leakage, score 2 corresponds to 1 to $50 \mathrm{~m}$ leakage, and score 3 corresponds to $>50 \mathrm{~m}$ leakage.

\section{Whole-Mount Immunostaining}

For whole-mount immunostaining, samples were fixed in $4 \%$ formaldehyde in PBS for 2 hours on ice. After washing twice in PBS, samples were permeabilized in PBS $0.1 \%$ TritonX-100 (PBST) and saturated for 2 hours in PBS containing 0.1\% TritonX-100 and 3\% milk (PBSMT) at RT. After washing twice in PBS, samples were incubated with primary antibodies: anti-mouse podoplanin from Developmental Studies Hybridoma Bank at $0.3 \mu \mathrm{g} / \mathrm{mL}$; rabbit anti-mouse Lyve-1 (Interchim 70R-LR005) at $2 \mu \mathrm{g} / \mathrm{mL}$, and rat anti-mouse CD31 (BD $553370)$ at $2.5 \mu \mathrm{g} / \mathrm{mL}$ in PBST overnight at $4^{\circ} \mathrm{C}$ with gentle agitation. Samples were washed every 15 minutes during 3 hours in PBST and incubated overnight at $4^{\circ} \mathrm{C}$ with secondary antibodies in PBST. Samples were then washed as described for the primary antibodies and mounted in Mowiol (Mowiol 4-88; Hoechst) supplemented with $2.5 \%$ antibleaching agent DABCO (Sigma-Aldrich, France). Images were recorded using an LSM780 laser scanning confocal microscope (Zeiss). Negative controls were performed with no primary antibody.

\section{Dermis Size Quantification}

Dermis size quantification was performed using 10 measurements of the length between epidermis and hypodermis per field, 6 tissue sections per mice, and 5 mice per group.

\section{Transcription Factor Motif Identifications}

Annotation of the promoter regions of Figf, Flt4, Has1, Has2, and Lyve1 genes was performed under the gene search algorithm included in the motifmap webservice (http://motifmap.ics.uci.edu/) ${ }^{28}$ We analyzed the DNA sequences ( $\mathrm{mm} 9$ genome annotation) corresponding to the $-5000 /+1000$-bp region surrounding the transcription starting site of each gene to search for transcription factor-binding sites. To ensure statistical significance, we retained as putative binding sites only those determined with a $Z$ score $>2$ and an FDR threshold $<0.5$. The DNA sequence corresponding to motifs resembling to ER-binding sites (binding sequences for $\mathrm{Hnf} 4 \alpha$ and other nuclear receptors) was retrieved from the UCSC browser (http://genome. ucsc.edu/ $/)^{29}$ and additionally visually inspected for its correspondence with known ER motifs.

\section{Cell Culture}

Human dermal LECs (HDLECs; Promocell, Heidelberg, Germany) were cultured in endothelial growth medium MV2 containing 5\% FBS (Promocell). Twenty-four hours before the experiments, culture media was replaced by endothelial growth medium MV2 phenol red free. Survival assay was performed using $1 \mathrm{nM} 17 \beta$ estradiol and $1 \mathrm{M}$ tamoxifen. Proliferation, migration, and branching assays were performed as described previously. ${ }^{30}$ Positive control consists in 5\% FBS and negative control consists in $0.5 \%$ serum with ethanol (1/1000).

\section{Microwave Sensor}

Mice were anesthetized with a subcutaneous injection of ketamine $(100 \mathrm{mg} / \mathrm{kg})$ and xylazine $(10 \mathrm{mg} / \mathrm{kg})$, and 5 measures were performed on 5 different locations to cover the entire edematous area. For each of them, a pulse of microwaves from 0 to $1.5 \mathrm{gHz}$ frequency, the incident wave, was applied to skin. Skin components, including fluids and ions, will thus either absorb or reflect a part of theses waves to induce a reflected wave. Reflected wave reflection, absorption, and delay were analyzed on each measure to determine the reflection coefficient phase of the skin. This coefficient directly correlates with the quantity of tissue fluids.

\section{Permeability Assay}

LECs were cultured under confluence for 3 days on cell culture inserts $(0.4 \mu \mathrm{M}$, Millicell) and then treated overnight with estradiol or Tamoxifen in $0.5 \%$ serum phenol-free medium as indicated in the figures. FITC-dextran $70 \mathrm{KD}(1 \mathrm{mg} / \mathrm{mL})$ was added and fluorescence intensity was measured at 30 minutes or 1 hour after in lower chamber by Tecan Infinite 500 .

\section{Western Blot Analysis}

Cells were harvested on ice, washed twice with cold PBS, collected, and frozen at $-80^{\circ} \mathrm{C}$. Dry pellets of cells were lysed in 50 $\mathrm{mmol} / \mathrm{L}$ Tris-HCl, pH 7.5, $150 \mathrm{mmol} / \mathrm{L} \mathrm{NaCl}, 1 \mathrm{mmol} / \mathrm{L}$ EDTA, $1 \%$ TritonX-100 (X100; Sigma) supplemented with protease and phosphatase inhibitors (sodium orthovanadate [S6508; Sigma], $1 \mathrm{mmol} / \mathrm{L}$ DTT, $2 \mathrm{mmol} / \mathrm{L} \mathrm{NaF}$ [S1504; Sigma], and complete Mini Protease Inhibitor Cocktail [ROCHE]). Protein concentration was measured using BCA Protein Assay Kit (Interchim), and equal amounts of proteins were subjected to SDS-PAGE and transferred onto nitrocellulose membrane (BioTraceNT, Pall Corp). Membranes were washed in Tris-buffered saline supplemented with $0.1 \%$ Tween-20 and then saturated in Tris-buffered saline supplemented with $0.1 \%$ Tween-20 with $5 \%$ nonfat dry milk, incubated overnight with primary antibodies in Tris-buffered saline supplemented with $0.1 \%$ Tween20 with 5\% BSA, washed and revealed according to Cell Signaling Technology protocol. Western blotting was conducted using standard methods with the following antibodies: p-Akt S473 (cat No. 4060, 1:2000; Cell Signaling Technology), pan-Akt (cat No. 4691S, 1:1000; Cell Signaling Technology), p-ERK1/2 (cat No. 4370, 1:1000; Cell Signaling Technology), GAPDH (6C5; cat No. sc-32233, $0.1 \mu \mathrm{g} / \mathrm{mL}$; Santa Cruz Biotechnology), and ER $\alpha$ clone 60C (N-term; cat No. 04-820, 1:2000; Millipore).

\section{Statistical Analysis}

All statistical analyses were performed using either a 2-tailed Student $t$ test for analyses of 2 groups or 1-way ANOVA for analyses 


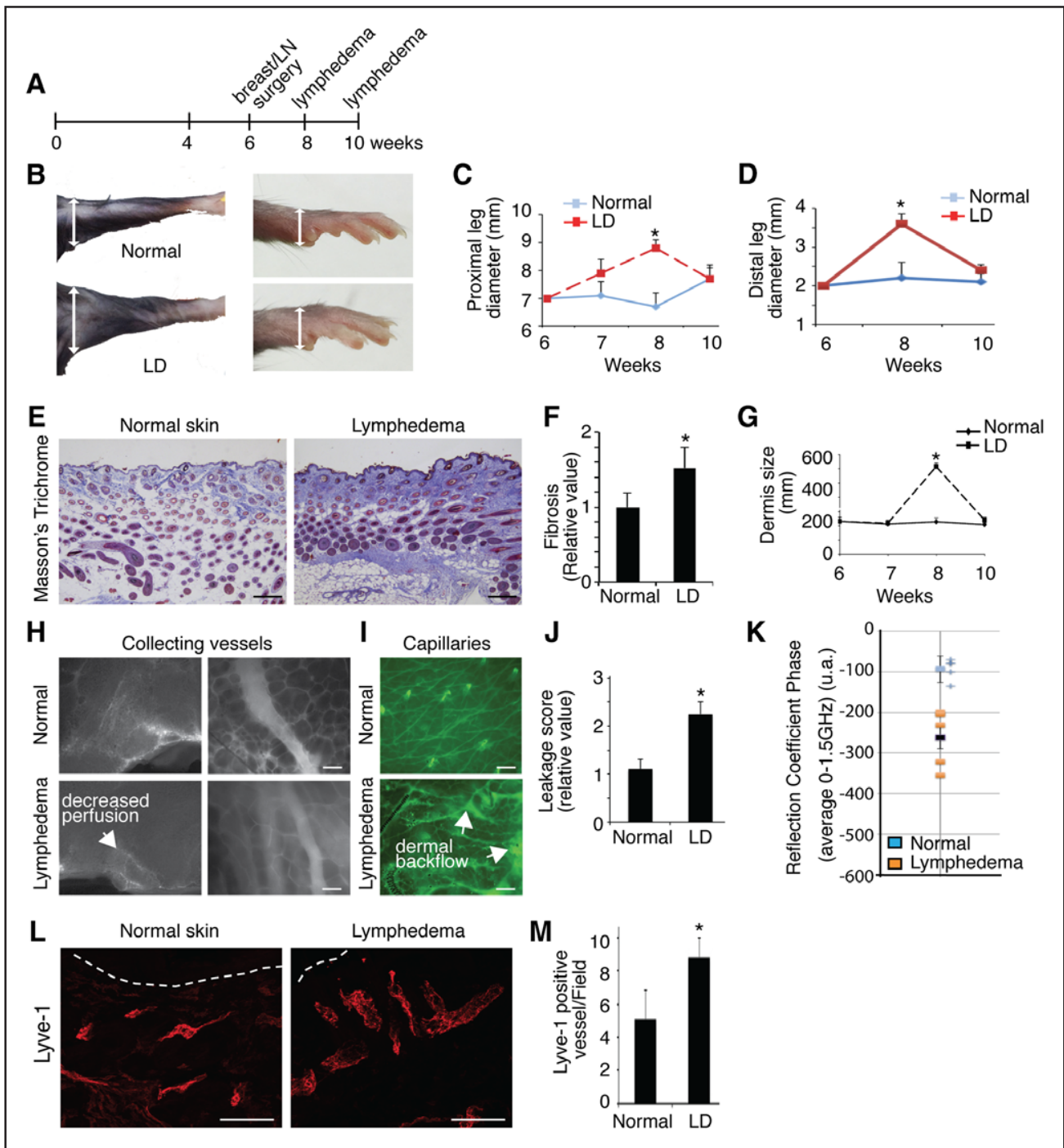

Figure 1. Mice experimental model of surgery-induced secondary lymphedema. A, Schematic representation of the experimental procedure. Mastectomy and lymphadenectomy are performed in 6-wk-old mice. B, Swelling develops 2 wk after surgery in proximal (left) and distal (right) part of the leg. C, Quantification of the proximal leg swelling revealing lymphedema 2 wk after surgery $(n=10)$. ${ }^{*} P<0.01$. D, Quantification of the distal leg swelling. ${ }^{*} P<0.01$. E, Masson trichrome staining of the skin from mice with lymphedema (scale bar=50 $\mu \mathrm{m})$. F, Fibrosis quantification (blue pixels) normalized to normal skin. ${ }^{\star} P<0.01$. G. Mouse lymphedema exhibits increase of dermis size 2 wk after surgery, ${ }^{*} P<0.001$. H, Fluorescence microlymphangiography revealed an altered lymphatic drainage in lymphedema (left) that is not associated with collecting vessel disruption (right; scale bar $=25 \mu \mathrm{m}$ ). I, Footpad FITC-dextran injection shows capillary dermal backflow in lymphedema (scale bar $=50 \mu \mathrm{m}$ ). $\mathbf{J}$, Relative quantification of dermal leakage in lymphedema. ${ }^{*} P<0.001$. $\mathbf{K}$, Electric properties of lymphedematous skin exhibit strong frequency dispersion in microwave bands, which translate into a specific signature as consequent of microwave radiation reflection and absorption. Lymphedematous leg exhibits delay in microwave reflection coefficient phase $(\mathrm{n}=5)$. $\mathbf{L}$, Skin immunodetection of the lymphatic vessels in lymphedema (scale bar=50 mm). M, Quantification of lymphatic vessel density in lymphedema. ${ }^{*} P<0.01$.

of $\geq 3$ groups. One-way ANOVA was followed by post hoc test of Bonferroni (Figures 1C, 1D, 2B, and 3A). All experiments were performed $3 \times$, where the quantification is reported as the average \pm SEM of 3 separate animal experiments, $* P<0.01$, **P<0.001.

\section{Results}

\section{ER $\alpha$ Targets Lymphangogenic Genes}

To determine whether the receptor ER $\alpha$ could control lymphatic-related genes, we first screened the sequences of the promoter regions of VEGF-D, VEGF-C, VEGFR-3, Lyve-1, and $H A S$ to identify potential DNA motifs able to mobilize ER (full or half-ERE and AP1; Figure 4A). We found ERE or
half-ERE in all genes except for VEGF-C (Figure 4A; Table I in the online-only Data Supplement). $V E G F-D$ and VEGFR-3 both contain a putative binding site for ER in their first intron. Hyaluronan receptor Lyve-1 and HAS-1 and HAS-2 were identified as containing AP1 and ERE/half-ERE sequences, respectively (Figure 4A). These data suggested a putative gene regulation by the ER. To confirm the regulation, we studied gene expression in vivo in estradiol-treated mice. Mice were ovariectomized at 4 weeks of age and implanted either with $17 \beta$ estradiol pellets ( $80 \mu \mathrm{g} / \mathrm{kg}$ per day) or with placeboreleasing pellets. Treatment was validated by the increase in uterine weight in estradiol-treated ovariectomized animals 
(Figure IA and IB in the online-only Data Supplement), and quantitative real-time PCR was performed on skin mRNA (Figure 4B through 4E). As expected, we found an upregulation of VEGF-D (Figure 4B), VEGFR-3 (Figure 4C), Lyve-1 (Figure 4D), and HASs (Figure 4E) in estradiol-treated animals. This upregulation was associated with an increase in skin lymphangiogenesis (Figure 4F and 4G). To confirm that estradiol could modify lymphatic-related genes in the lymphatic endothelium, we investigated the expression of LYVE-1 and VEGFR-3 in LECs in vitro. We first confirmed by quantitative real-time PCR and Western blot that HDLECs express only the receptor $\operatorname{ER} \alpha$, but not $\operatorname{Er} \beta$, suggesting a selective effect of this receptor in lymphatic endothelium (Figure IC and ID in the online-only Data Supplement). As HDLECs are isolated from male foreskin, we wondered whether sex gender could influence the ER $\alpha$ expression in tissues to eliminate bias related to gender cell origins (Figure IE in the online-only Data Supplement). As expected, we could not find any tissuespecific variation between male and female. Interestingly, we found an activation of Lyve- 1 and VEGFR-3 mRNA expression in estradiol-stimulated HDLEC (Figure 4H and 4I). To further demonstrate that the effect of estradiol is mediated by $\mathrm{ER} \alpha, \mathrm{ER} \alpha$ was knocked down using shRNA in HDLECs (Figure 4J). The depletion of ER $\alpha$ using shRNA abolished the induction of the ER $\alpha$-targeted gene VEGF-A induced by estradiol (Figure IF in the online-only Data Supplement). Also, the increase of VEGFR-3 and LYVE-1 expression induced by estrogen treatment was abolished in shER $\alpha$-transfected cells confirming that ER $\alpha$ mediates lymphatic gene expression in LECs in response to estradiol (Figure $4 \mathrm{~K}$ and $4 \mathrm{~L}$ ).

\section{Mice Model of Secondary Lymphedema}

To study whether estrogen level may influence lymphatic function in secondary lymphedema, we established an original mouse model of lymphedema induced by second mammary gland mastectomy associated with axillary and brachial lymphadenectomy on 6-week-old C57B1/6 female mice (Figure 1A; Figure IIA in the online-only Data Supplement). In this model, mice sustained reproducible edema for a period of $>2$ weeks as limb volume measurements systematically peaked 2 weeks after the surgery procedure with a volume increase of $20 \%$ to $25 \%$ in proximal (axillary) and distal (foot) part of the leg (Figure 1B). Then, resolution of edema consistently occurred after 4 weeks (Figure 1C and 1D). Using Masson trichrome coloration, we observed clinical signs occurring in lymphedema, including skin fibrosis (Figure $1 \mathrm{E}$ and $1 \mathrm{~F}$ ) and increased dermis thickness (Figure 1G). Lymphatic circulation was next investigated in collecting vessels and in capillaries using intralymphatic injection of dextran-FITC. The overall lymphatic perfusion was decreased in lymphedematous limb without any effect on collecting vessel shape (Figure $1 \mathrm{H}$ ). In contrast, we observed an important lymphatic leakage (dermal backflow) in superficial capillary network (Figure 1I) as shown by the lymphatic leakage score (Figure 1J). Early detection of lymphedema is a major challenge in the patient health care. For this purpose, we developed an original device based on microwave reflection analysis to detect early swelling (Figure 1K; Figure IIB in the online-only Data Supplement). Microwave relies on the specific electric properties of living tissues, such as skin, muscle, fat, and many others, which are different from those of gazes (air) or other solid and nonbiological material (glass or plastic). We observed a shift in reflection coefficient phase relative to limb edema (Figure $1 \mathrm{~K}$ ). This alteration of lymphatic function in our mice model of lymphedema was accompanied by an increase of lymphatic vessel density in skin (Figure 1L and $1 \mathrm{M}$ ) indicating a strong activation of lymphangiogenesis during the onset of lymphedema.

\section{Secondary Lymphedema Is Prevented by Estrogens but Is Aggravated by Tamoxifen Treatment}

Deciphering whether estrogen could play a role in lymphatic function remains a crucial challenge for breast cancer-related lymphedema because for decades, selective ER modulators, such as tamoxifen, are used in first line of hormone therapy for women who develop breast cancer. Toward this aim, mastectomy and lymph node dissection were performed on OVX mice implanted with estradiol, tamoxifen, or placebo pellets 2 weeks before surgery (Figure 2A). Remarkably, edema was observed in OVX group and was exacerbated by blocking ER $\alpha$ using tamoxifen. Notably, the protective effect of estradiol on lymphedema was abolished by tamoxifen, and lymphedema was maintained 4 weeks after surgery (Figure 2B). Estradiol and tamoxifen did not induce modifications of the basal lymphatic network architecture in ear skin (Figure III in the online-only Data Supplement). In contrast, in the context of lymphedema, we observed an induction of skin lymphangiogenesis in both estradiol and tamoxifen-treated groups (Figure 2C and 2D). Despite an absence of modification in lymphatic vessel density between estradiol and tamoxifen treatment, we observed an important lymphatic leakage (arrows) in superficial capillaries network in OVX mice that was prevented by estradiol treatment showing a protective effect of estradiol on the endothelial barrier (Figure 2E). On the opposite, tamoxifen aggravated the dermal backflow that was, in part, reduced by estradiol (Figure 2E and 2F). Interestingly, deeper lymphatic collecting vessels were not affected by tamoxifen confirming an impact restricted to the capillary network (Figure 2G). This effect was associated with changes in water and ion contents as assessed using microwave sensor showing a shift between estradiol and tamoxifen (Figure 2H).

Estrogens are potent anti-inflammatory regulators of cutaneous healing. ${ }^{31}$ To evaluate whether estradiol and tamoxifen could have an effect on the inflammatory status, immune response was analyzed by flow cytometry in brachial and axillary lymph nodes to evaluate the systemic inflammation (Figure 2I and 2J). Estradiol partially decreased F4/80-positive macrophages, and this effect was not abolished by tamoxifen (Figure 2I). Lymphatic injury increased the number of macrophages and favored M2 differentiation as observed previously in the mouse tail model of lymphedema. ${ }^{32}$ Our findings suggest that macrophages home to lymphedematous tissues and differentiate into the M2 phenotype. Surprisingly, tamoxifen had no major effect compared with estradiol on the inflammatory process in our model (Figure 2J). As we previously demonstrated the role of estradiol on controlling lymphangiogenic genes expression, we wondered whether tamoxifen 


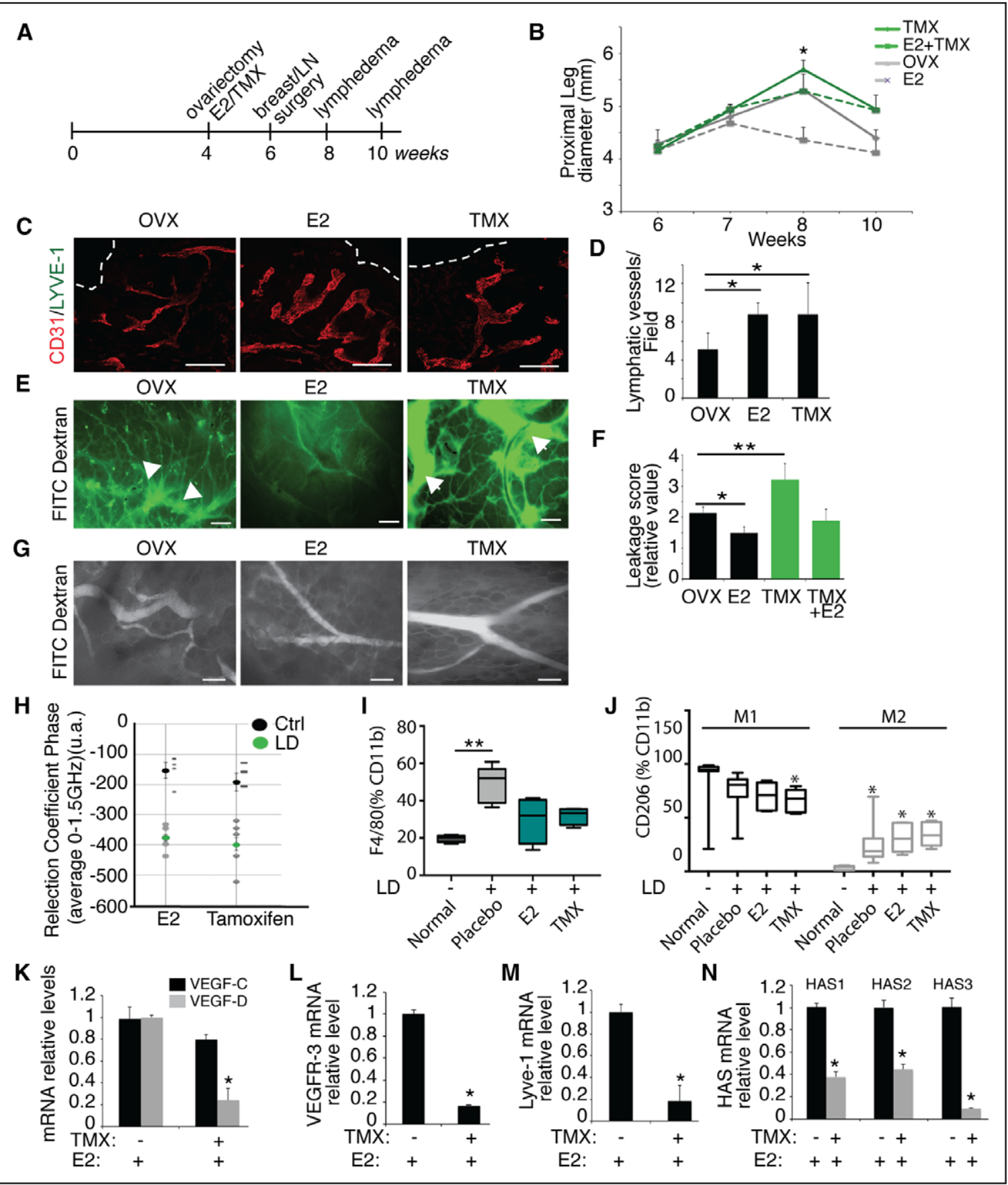

Figure 2. Tamoxifen (TMX) inhibits beneficial effect of estrogen on lymphatic endothelium. A, Schematic representation of the experimental procedure. Sixty-day released estradiol (E2) or TMX subcutaneous pellets are implanted 2 wk before lymphedema surgery. B, Mice proximal leg diameter measurement shows that TMX aggravates swelling and inhibits the reduction of edema 4 wk after surgery ( $n=10)$. C, Skin immunodetection of the lymphatic vessels in E2 or TMX-treated lymphedematous leg (scale bar=50 mm). D, Quantification of lymphatic vessel density. E, FITC-dextran intralymphatic injections revealed leaky lymphatic capillaries in edematous skin in that is reduced by E2 and aggravated by TMX (scale bar=50 $\mu \mathrm{m}$ ). F, Relative quantification of the leakage shows that E2-improved lymphatic drainage is antagonized by TMX. G, FITC-dextran intralymphatic injections revealed that TMX did not induce collecting vessels leakage. $\mathbf{H}$, The deleterious effect of TMX is characterized by a delay in microwave reflection. I and J, Flow cytometry analysis of the F4/80-positive (I) and M1/M2 macrophages (J) in E2- or TMX-treated mice with 4-wk lymphedema. K, Quantitative real-time polymerase chain reaction (RTPCR) shows that TMX inhibits E2-induced VEGF (vascular endothelial growth factor)-D but not VEGF-C expressions. L-N, Quantitative RT-PCR shows that TMX inhibits E2-induced VEGFR-3 (L), Lyve-1 (M), and HAS (hyaluronan synthase)-1, 2, and 3 (N) mRNA expression in skin. ${ }^{*} P<0.01,{ }^{\star \star} P<0.001$.

could abolish the effect of estradiol on lymphedematous skin. Mechanistically, we found that tamoxifen blocked estradiolinduced VEGF-D (Figure 2K), VEGFR-3 (Figure 2L), Lyve-1 (Figure 2M), and HAS (hyaluronan synthases)-1, HAS2, and HAS3 (Figure 2N) gene expression. Taken together, our results highlight that estrogen plays a protective role on lymphatic endothelium during the pathological condition of lymphedema. 


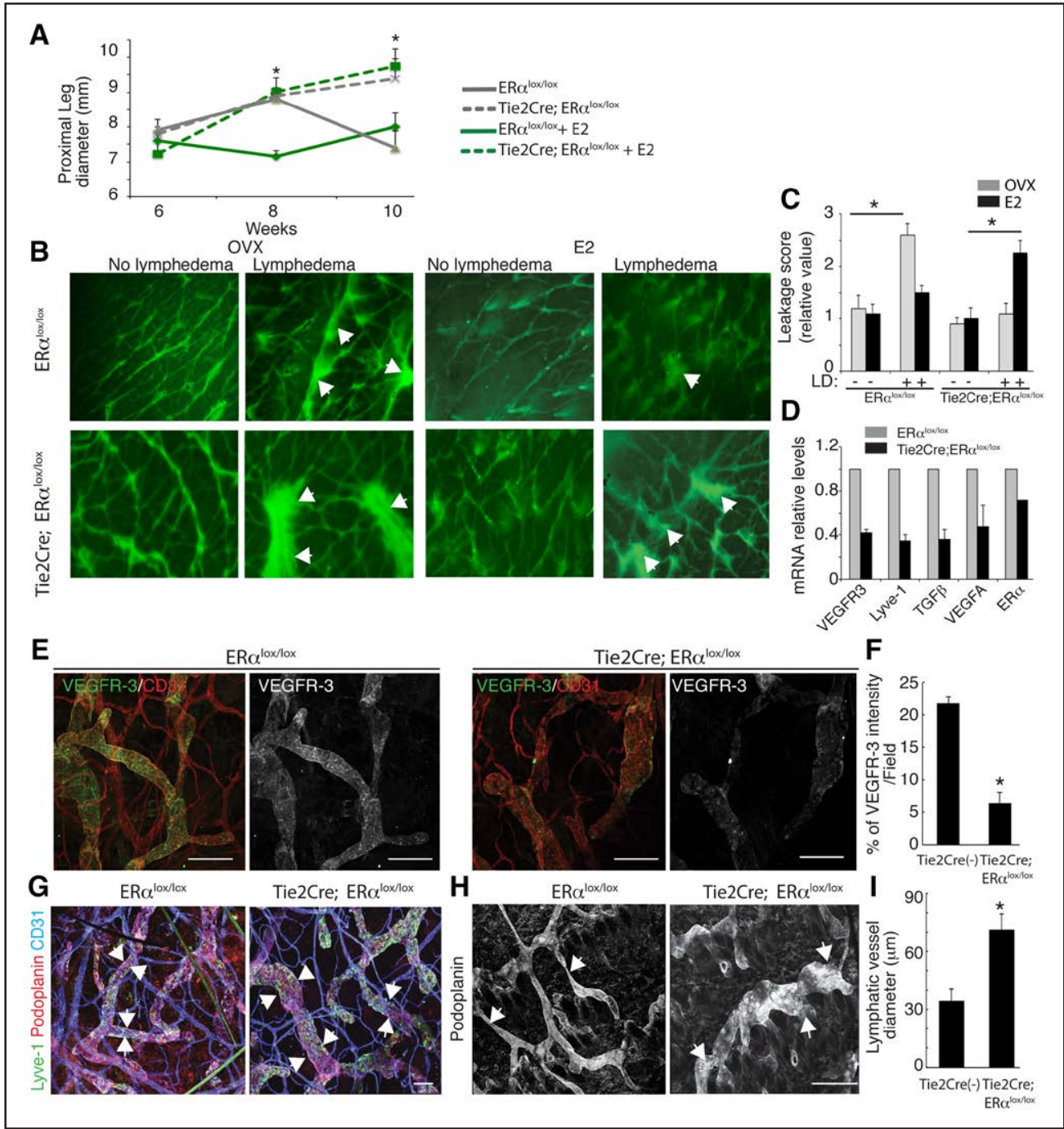

Figure 3. Estrogen-protective effect on lymphatic endothelium is mediated by the estrogen receptor (ER) $\alpha$. A, Leg measurement shows

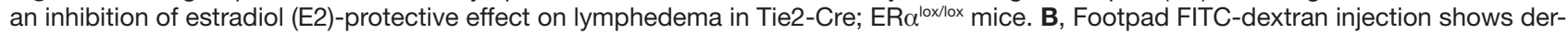

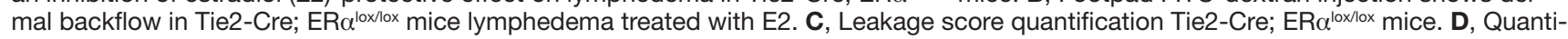
tative real-time polymerase chain reaction on Tie2-Cre; ER $\alpha^{\text {loxlox }} \mathrm{mRNAs}$ from sorted lymphatic endothelial cells (LECs) show an inhibition of VEGFR (vascular endothelial growth factor receptor)-3, Lyve-1, TGFb, VEGF-A, and ER $\alpha$ expression compared with ER $\alpha^{\text {lox/lox }}$ LECs. E, Immunostaining for CD31 and VEGFR-3 shows a decrease of VEGFR-3 expression on lymphatic capillaries in Tie2-Cre; ER $\alpha^{\text {lox/lox }}$ mice (scale bar=200 $\mu \mathrm{m}$ ). F, Quantification of VEGFR-3 immunodetection on lymphatic vessels. G, Immunostaining for Lyve-1 (green), podoplanin (red), and CD31 (blue) in control skin revealed dilated lymphatic vessels in Tie2-Cre; ER $\alpha^{\text {lox/lox }}$ mice compared with control ER $\alpha^{\text {lox/lox }}$ mice (scale bar=200 $\mu \mathrm{m})$. H, Immunostaining for podoplanin in lymphedematous skin shows dilated lymphatic vessels in Tie2-Cre; ER $\alpha^{\text {lox/ }}$ lox mice (scale bar=200 $\mu \mathrm{m}$ ). I, Quantification of the lymphatic vessel diameter in lymphedematous skin. ${ }^{\star} P<0.01$.

\section{Protective Effect of Estrogens on Lymphatic Endothelium Is Mediated by ER $\alpha$}

To better understand the role of ER $\alpha$ on the lymphatic system, we performed experiments in mice deleted for ER $\alpha$ in the endothelium using the Tie2-Cre; ERa $\alpha^{\text {loxlox }}$ mice model. ${ }^{33,34}$ The deletion of ER $\alpha$ in the lymphatic endothelium was validated in Tie2-Cre; $m T m G$ mice (Figure IV in the online-only Data Supplement). No significant difference in VE-cadherin button-like junctions was observed in lymphatic capillaries from Tie2-Cre; ER $\alpha^{\text {flox/flox }}$ mice compared with control ER $\alpha^{\text {flox/flox }}$ mice (Figure VA in the online-only Data Supplement). In parallel, the KI-67 immunodetection did not reveal major modification in skin vessel proliferation in Tie2-Cre; ER $\alpha^{\text {flox/flox }}$ mice compared with control (Figure
VB in the online-only Data Supplement). In lymphedema model, we observed an inhibition of the protective effect of estradiol in estradiol-treated Tie2-Cre; $E R \alpha^{l o x} / / 0 x$ mice because the edema is induced 2 weeks after surgery, despite the estrogen treatment (Figure 3A). As observed with tamoxifen, the edema was maintained after 4 weeks, whereas it was resolved in $E R \alpha^{l o x / l o x}$ estradiol-treated mice (Figure 3A). The inhibition of the protective effect of estradiol on lymphatic endothelium was confirmed by intralymphatic dye injection showing an important dermal backflow in Tie2-Cre; $E R \alpha^{\text {lox/lox }}$ mice compared with $E R \alpha^{l o x / l o x}$ (Figure 3B and 3C). As we previously showed that estradiol regulates VEGFR-3 and LYVE-1 gene expression in vivo and in vitro (Figure 4), we first analyzed expression of these genes by quantitative real-time 


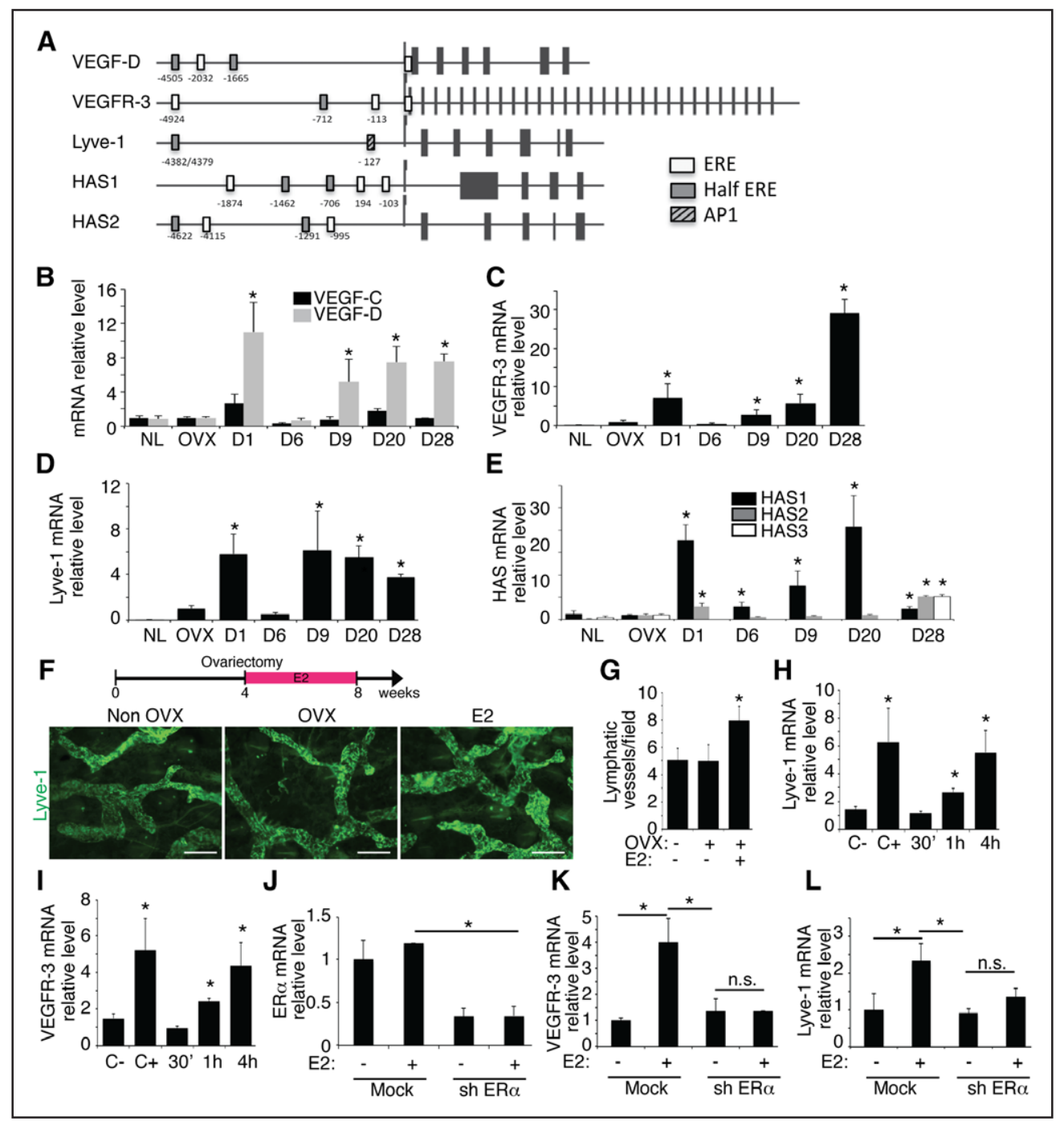

Figure 4. ER (estrogen receptor)- $\alpha$ targets lymphangogenic genes. A, Schematic representation of ER-binding sites (estrogen response element [ERE] and AP1) on VEGF (vascular endothelial growth factor)-D, VEGFR-3, Lyve-1, HAS (hyaluronan synthase) 1, and HAS2 on $-5000 /+1000$-bp region surrounding the transcription starting site. B-E, Quantitative real-time polymerase chain reaction (RT-PCR) of VEGF-C and VEGF-D (B), VEGFR-3 (C), Lyve-1 (D), and HAS1, 2, and 3 (E) mRNAs in skin from mice treated with estradiol (E2) during 28 $\mathrm{d}$ and compared with control (NL) or OVX (ovariectomized) mice. F, Skin immunodetection of the lymphatic vessels in E2-treated mice (4-wk treatment) compared with OVX and non-OVX mice (scale bar=100 mm). G, Quantification of lymphatic vessel density in the skin from E2-treated mice compared with OVX and non-OVX. H and I, Quantitative RT-PCR of Lyve-1 (H) and VEGFR-3 (I) mRNAs in E2-stimulated human dermal lymphatic endothelial cells (HDLECs) compared with $0.5 \%$ SVF (C-) or $5 \%$ SVF (C+). J, Quantitative RT-PCR of ER $\alpha$ mRNA in HDLEC after ERa shRNA transfection. K, Quantitative RT-PCR of VEGFR-3 mRNA in HDLEC after ER $\alpha$ shRNA transfection. L, Quantitative RT-PCR of Lyve-1 mRNA in HDLEC after ER $\alpha$ shRNA transfection. ${ }^{*} P<0.01$.

PCR in isolated LECs from Tie2-Cre; ER ${ }^{\text {lox/lox }}$ mice. LEC sorted from these mice exhibited a decrease in VEGFR-3 and Lyve-1 mRNA, as well as ER-targeted genes, such as TGF $\beta$ and VEGF-A, and ER $\alpha$ expression (Figure 3D). In addition, decrease of VEGFR-3 expression was confirmed at protein level by whole-mount immunostaining on Tie2Cre; $E R \alpha^{l o x / l o x}$ mice compared with $E R \alpha^{l o x / l o x}$ mice (Figure 3E and $3 \mathrm{~F}$ ). Interestingly, the absence of ER $\alpha$ revealed enlarged and dilated vessels suggesting a higher permeability of the lymphatic endothelium (Figure 3G). Consequently, the loss of proper function of the lymphatic vessel observed in Tie2Cre; $E R \alpha^{l o x h l o x}$ mice was aggravated in lymphedematous skin with the presence of enlarged and tortuous lymphatic vessels (Figure $3 \mathrm{H}$ and $3 \mathrm{I}$ ).

\section{Estradiol-Induced LEC Function In Vitro Is Mediated by Erk Pathway}

Because dilated and permeable lymphatic vessels observed in the absence of ER $\alpha$ signaling (Figure 3) or on tamoxifen treatment (Figure 2) may relate to an alteration in the junctional organization of lymphatic vessels, we first wondered whether estradiol could modulate LEC cell-cell junctions in vitro (Figure 5A). Intriguingly, estradiol preserves LEC junctions at a comparable level to serum treatment (Ctrl+). In contrast, tamoxifen downregulates VE-cadherin at membrane level, and this effect correlated with a decrease in cortical actin fibers (Figure 5A). In the context of lymphedema, we previously showed that estrogen signaling is required to repair a functional lymphatic network. Therefore, we next investigated the role of estradiol on LEC 


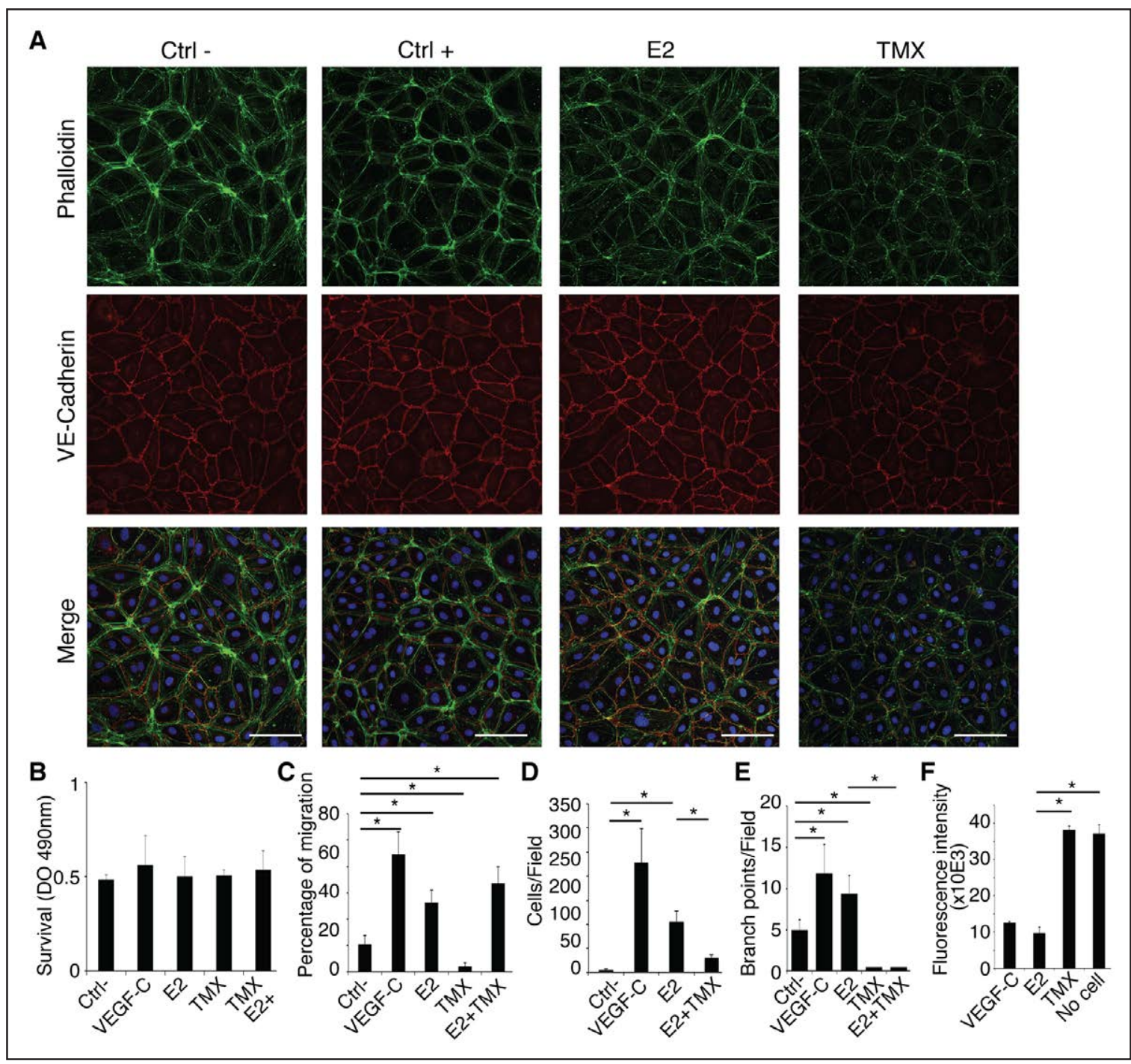

Figure 5. Tamoxifen (TMX) inhibits lymphatic endothelial cell function in vitro. A, Phalloidin (green) and VE-cadherin (red) immunostaining on human dermal lymphatic endothelial cell (HDLEC) unstimulated (Ctrl: $0.5 \%$ SVF) or stimulated by VEGF (vascular endothelial growth factor)-C (Ctrl+: $30 \mathrm{ng} / \mathrm{mL})$, estradiol (E2; $1 \mathrm{nM})$, and TMX (1 mmol/L) shows a slight increase of VE-cadherin expression with E2. TMX induces a downregualtion of VE-cadherin expression associated to an alteration of cortical actin organization at cellular junctions (scale bar=50 $\mu \mathrm{m})$. B, E2 and TMX have no effect on HDLEC survival. C, Quantification of the percentage of HDLEC migration using scratch wound healing assay shows an inhibition of E2-induced migration by TMX. D, Quantification of the percentage of HDLEC migration using Boyden chamber shows an inhibition of E2-induced migration by TMX. E, TMX antagonizes E2-induced HDLEC branching in matrigel. F, HDLEC monolayer exhibits higher transendothelial permeability in the presence of TMX. ${ }^{*}<0.01$.

functions in vitro by performing survival, migration, branching, and permeability assays (Figure 5B through $5 \mathrm{~F}$ ). ${ }^{35}$ Blocking ERav with tamoxifen did not alter cell survival (Figure 5B). We found that tamoxifen inhibited estradiol-induced LEC migration both in scratch (Figure 5C) and transwell (Figure 5D) migration assays. The role of estradiol on LEC sprouting in matrigel was further evaluated (Figure 5E). Estradiol promoted an induction of LEC branching in vitro that was inhibited by tamoxifen (Figure 5E). In contrast, estradiol did not induce LEC monolayer permeability, whereas tamoxifen strongly promoted the transendothelial diffusion of FITC-Dextran (Figure 5F).

\section{Plasma Membrane ER $\alpha$}

There are 2 subcellular localizations of the ER: a nuclear localization that mediates its transcriptional activity and a plasma membrane localization that promotes activation of nongenomic signaling pathway (Figure 6A). To identify this nongenomic estradiol-induced signaling in LECs, we studied Akt and Erk phosphorylation in vitro (Figure 6B through 6D). Immunoblot analysis of PS473-Akt and P-Erk on LEC showed a strong and rapid stimulation of the phosphorylation induced by estradiol after 30 minutes (Figure 6B). Surprisingly, tamoxifen did not antagonize estradiol-induced PS473-Akt phosphorylation (Figure 6C). In the opposite, tamoxifen inhibited estradiol-induced Erk phosphorylation, suggesting a pivotal role of Erk pathway in the beneficial effect of estradiol on lymphatic endothelium (Figure 6D). To confirm this hypothesis, LEC migration assays were performed in presence of MEK inhibitor. We observed an inhibition of LEC migration in scratch (Figure 6E) and transwell 


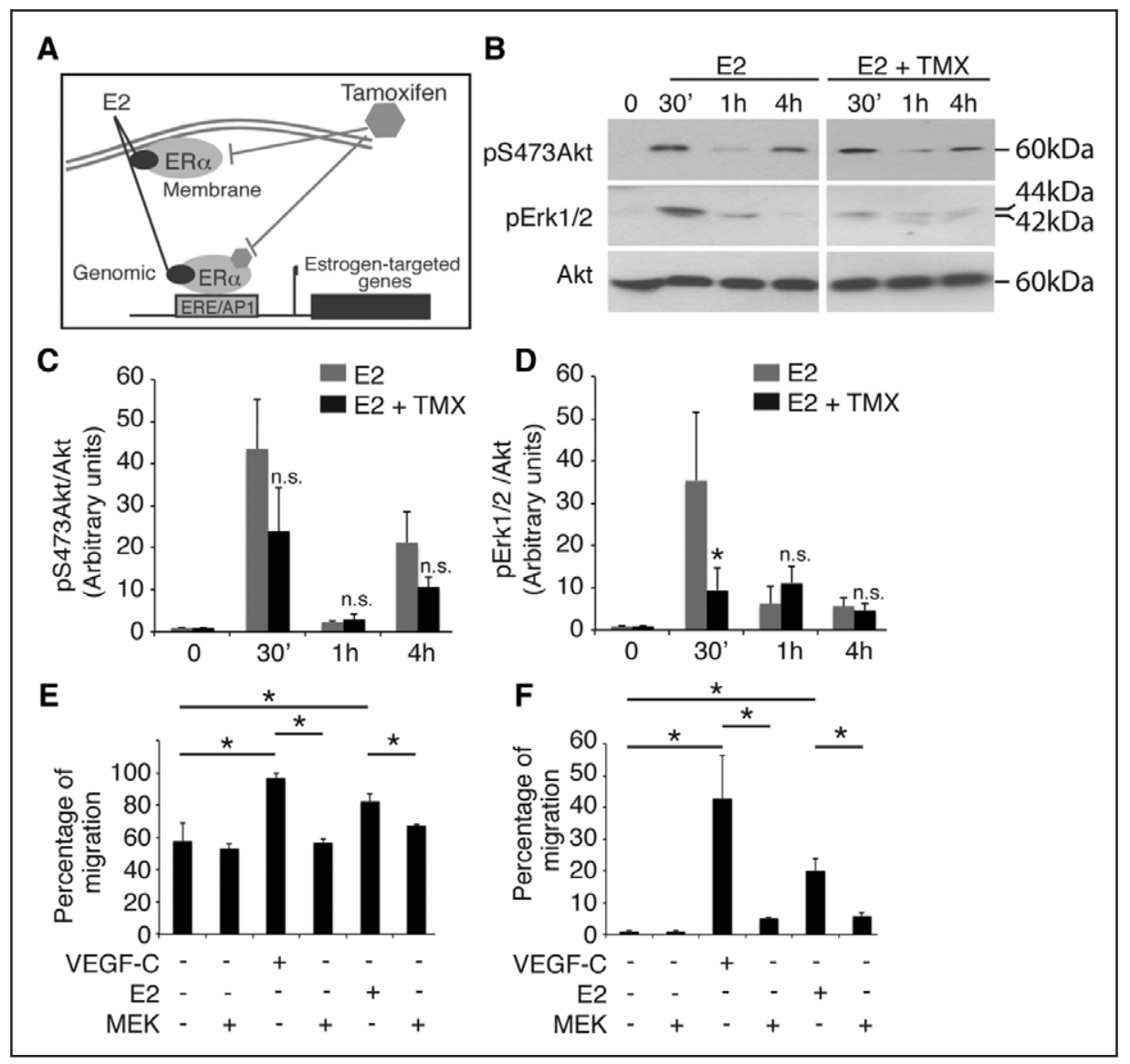

Figure 6. Tamoxifen (TMX) inhibits estradiol (E2)-induced ERK signaling. A, Schematic representation of TMX action on nuclear- and membrane-initiated effect of ER (estrogen receptor). B, Immunoblot of pS473-Akt, pErk1/2, and Akt in human dermal lymphatic endothelial cells (HDLECs) stimulated by E2 and E2+TMX. C and D, Relative levels of phosphorylated S473Akt (C) and Erk1/2 (D) normalized to total Akt. E, Quantification of the percentage of E2-induced HDLEC migration using scratch wound healing assay shows an inhibition by MEK inhibitor. F, Quantification of the percentage of E2-induced HDLEC migration using Boyden chamber shows an inhibition by MEK inhibitor. ${ }^{\star} P<0.01$.

(Figure 6F) migration assays demonstrating the crucial role of Erk pathway in nongenomic estradiol-induced LEC activation. These data suggested that estrogens mobilize activation of 2 pools of ER $\alpha$ in LEC, both the canonical nuclear transcriptional activity and the plasma membrane-induced signaling cascade (Figure 6).

\section{Discussion}

Despite the large body of evidence showing that sex hormones, in particular estrogens, influence lymphatic function, surprisingly little is known about the mechanisms of estrogen regulation on lymphatic endothelium. In this study, we identified a crucial role of estrogens in protecting lymphatic endothelium during secondary lymphedema. Then, we studied the impact of a selective ER modulator, tamoxifen, on lymphedema incidence. Estradiol is ubiquitous hormone generally thought to be a female hormone but is also produced in male and targets the organism in a same extent as estradiol response is observed in postmenopausal women, as well as in transgender men. This response is associated with the expression of the receptor ER $\alpha$ that is similar in male and female. Here, we determined that the expression of ER $\alpha$ in LEC is restricted to the isoform $\alpha$, which is a major difference with blood EC that express both ER $\alpha$ and $\beta .{ }^{36}$ Using genome analysis, we found that estradiol targets VEGFR-3, VEGF-D, Lyve-1, and HAS gene expression. Therefore, we postulated that blocking estrogen function might have a direct impact on lymphatic function and then in lymphedema. Estrogens have been known for decades to have beneficial effects on the skin because they represent critical regulators of dermal hyaluronan. ${ }^{37}$ Hyaluronan plays a key role in regulating lymphangiogenesis by providing the fundamental matrix for LEC function. ${ }^{38}$ To better dissect molecular mechanism involved in secondary lymphedema, we developed an original mouse model of unilateral secondary lymphedema. As we postulated that lymphedema is not only a side effect of surgery, we hypothesized that edema will worsen by hormone treatment. We found that estradiol prevents lymphedema development. This effect seems to be restricted to lymphatic capillaries because deeper collecting vessels are not affected by estrogen treatment. These observations are in opposite with the effect on blood microvascular vessels in which estradiol induces a rapid increase of permeability because of the stimulation of $V E G F-A$ gene expression. ${ }^{39-41}$ In fact, secondary lymphedema leakage is associated with a blockade of the lymph flow from the tissue to the lymphatic vessels leading to an accumulation of fluids into 
tissues. In that context, estrogens ameliorate lymphatic function and significantly reduce the dermal backflow.

Secondary lymphedema mostly occurs after breast cancer. Women with early-stage breast cancer receive $\leq 5$ years of adjuvant treatment with tamoxifen-an inhibitor of ER. We found that blocking ER $\alpha$ using tamoxifen is an aggravating factor for lymphedema because swelling is not resolved compared with OVX or estradiol-treated mice. This deleterious effect of blocking $\mathrm{ER} \alpha$ was confirmed using TieCre; $E R \alpha^{\text {lox/lox }}$ mice that exhibit long-term swelling. These mice show a strong dermal lymphatic backflow associated with hyperplastic and dilated vessels representative of fluid stasis. Mechanistically, we found that loss of ER $\alpha$ reduces lymphangiogenic gene expression VEGFR-3 and LYVE-1 in vivo and in vitro. Therefore, it will be particularly interesting to further investigate the function of ER $\alpha$ in lymphatic endothelium by generating $\mathrm{ER} \alpha$ lymphatic-specific KO mice models to discriminate the lymphatic-specific effect of estradiol and its role on extracellular matrix remodeling. The selective inhibition of ER $\alpha$ in LEC by tamoxifen did not affect survival or proliferation demonstrating a major discordance with mammary epithelial cells in which tamoxifen induces apoptosis. ${ }^{42}$ Traditionally, estrogen signaling is thought to be mediated through genomic pathways. However, estrogen stimulation of cells leads to rapid nongenomic effects, including Akt and Erk phosphorylation. Here, we demonstrated that estradiol-induced Erk, but not Akt phosphorylation, is inhibited by tamoxifen in LECs. One of the main consequences of estrogen inhibition in vitro is to inhibit LEC migration and tube formation.

Altogether, these observations suggest that hormone therapy interferes with lymphatic vasculature stability, more than lymphatic growth. These data are in accordance with human secondary lymphedema that develop months, sometimes years, after surgery demonstrating a preexisting, even dysfunctional, lymphatic system. Hormone therapy could thus increase the lymphatic dysfunction more than lymphatic regeneration immediately after surgery. This deleterious effect is aggravated by a stimulus years after surgery that induces a disruption of this damaged endothelium to induce a massive leakage. Our study establishes the pivotal role of hormones, in particular estrogens, in the healing of the lymphatic endothelium. It will provide significant knowledge to better anticipate and understand the pathology to improve the medical aspects of patient care.

\section{Acknowledgments}

We thank Jean-François Arnal for his scientific support, Jean-José Maoret for his technical support, and Y. Barreira from the platform Anexplo Genotoul (Inserm US006, Toulouse, France) for his outstanding technical assistance. We thank the imaging platform of Institute of Metabolic and Cardiovascular Diseases of Toulouse (I2MC) for its scientific and technical support. We thank Dr Masri for providing the ERK inhibitor and Cathrin Brisken for the ER (estrogen receptor)- $\alpha$ shRNA. These studies were conducted using molecular biology-shared resources from the I2MC.

\section{Sources of Funding}

This work has been supported by the Ligue Régionale Contre le Cancer (RPT15002BBA), the foundation ARC pour la Recherche sur le Cancer (RAC15003BBA), IDEX Paul Sabatier Federal University
(RGE14001BBA), and the Toulouse Cancer Santé Fondation. We thank Lefoulon Delalande fundation and Region Occitanie.

\section{Disclosures}

None.

\section{References}

1. Arnal JF, Gourdy P, Elhage R, Garmy-Susini B, Delmas E, Brouchet L, Castano C, Barreira Y, Couloumiers JC, Prats H, Prats AC, Bayard F. Estrogens and atherosclerosis. Eur J Endocrinol. 2004;150:113-117.

2. Chambliss KL, Shaul PW. Estrogen modulation of endothelial nitric oxide synthase. Endocr Rev. 2002;23:665-686. doi: 10.1210/er.2001-0045.

3. Mendelsohn ME, Karas RH. Molecular and cellular basis of cardiovascular gender differences. Science. 2005;308:1583-1587. doi: $10.1126 /$ science. 1112062 .

4. Levin ER. Integration of the extranuclear and nuclear actions of estrogen. Mol Endocrinol. 2005;19:1951-1959. doi: 10.1210/me.2004-0390.

5. Thornton JW, Need E, Crews D. Resurrecting the ancestral steroid receptor: ancient origin of estrogen signaling. Science. 2003;301:1714-1717. doi: 10.1126/science.1086185.

6. Krust A, Green S, Argos P, Kumar V, Walter P, Bornert JM, Chambon P. The chicken oestrogen receptor sequence: homology with v-erbA and the human oestrogen and glucocorticoid receptors. EMBO J. 1986;5:891-897.

7. Brouchet L, Krust A, Dupont S, Chambon P, Bayard F, Arnal JF. Estradiol accelerates reendothelialization in mouse carotid artery through estrogen receptor-alpha but not estrogen receptor-beta. Circulation. 2001;103:423-428.

8. Arnal JF, Fontaine C, Abot A, Valera MC, Laurell H, Gourdy P, Lenfant F. Lessons from the dissection of the activation functions (AF-1 and AF-2) of the estrogen receptor alpha in vivo. Steroids. 2013;78:576-582. doi: 10.1016/j.steroids.2012.11.011

9. Klinge CM. Estrogen receptor interaction with estrogen response elements. Nucleic Acids Res. 2001;29:2905-2919.

10. Li C, Briggs MR, Ahlborn TE, Kraemer FB, Liu J. Requirement of Sp1 and estrogen receptor alpha interaction in 17beta-estradiol-mediated transcriptional activation of the low density lipoprotein receptor gene expression. Endocrinology. 2001;142:1546-1553. doi: 10.1210/endo.142.4.8096.

11. Stossi F, Likhite VS, Katzenellenbogen JA, Katzenellenbogen BS. Estrogen-occupied estrogen receptor represses cyclin G2 gene expression and recruits a repressor complex at the cyclin G2 promoter. J Biol Chem. 2006;281:16272-16278. doi: 10.1074/jbc.M513405200.

12. Razandi M, Pedram A, Park ST, Levin ER. Proximal events in signaling by plasma membrane estrogen receptors. J Biol Chem. 2003;278:2701-2712. doi: $10.1074 /$ jbc.M205692200.

13. Levin ER. Cellular functions of plasma membrane estrogen receptors. Steroids. 2002;67:471-475.

14. Shu YY, Maibach HI. Estrogen and skin: therapeutic options. Am J Clin Dermatol. 2011;12:297-311. doi: 10.2165/11589180-000000000-00000.

15. Jackson DG. Immunological functions of hyaluronan and its receptors in the lymphatics. Immunol Rev. 2009;230:216-231. doi: 10.1111/j.1600-065X.2009.00803.x.

16. Schrott HG, Bittner V, Vittinghoff E, Herrington DM, Hulley S. Adherence to National Cholesterol Education Program Treatment goals in postmenopausal women with heart disease. The Heart and Estrogen/Progestin Replacement Study (HERS). The HERS Research Group. JAMA. 1997;277:1281-1286.

17. Alitalo K, Tammela T, Petrova TV. Lymphangiogenesis in development and human disease. Nature. 2005;438:946-953. doi: 10.1038/nature04480.

18. Greene R, Fowler R. Physical therapy management of primary lymphedema in the lower extremities: a case report. Physiother Theory Pract. 2010;26:62-68. doi: 10.3109/09593980802667854.

19. Smeltzer DM, Stickler GB, Schirger A. Primary lymphedema in children and adolescents: a follow-up study and review. Pediatrics. 1985;76:206-218.

20. Sener SF, Winchester DJ, Martz CH, Feldman JL, Cavanaugh JA, Winchester DP, Weigel B, Bonnefoi K, Kirby K, Morehead C. Lymphedema after sentinel lymphadenectomy for breast carcinoma. Cancer. 2001;92:748-752.

21. Petrova TV, Karpanen T, Norrmén C, Mellor R, Tamakoshi T, Finegold D, Ferrell R, Kerjaschki D, Mortimer P, Ylä-Herttuala S, Miura N, Alitalo K. Defective valves and abnormal mural cell recruitment underlie lymphatic vascular failure in lymphedema distichiasis. Nat Med. 2004;10:974-981. doi: 10.1038/nm1094. 
22. Slavin SA, Van den Abbeele AD, Losken A, Swartz MA, Jain RK. Return of lymphatic function after flap transfer for acute lymphedema. Ann Surg. 1999;229:421-427.

23. Specht MC, Miller CL, Skolny MN, Jammallo LS, O'Toole J, Horick N, Isakoff SJ, Smith BL, Taghian AG. Residual lymph node disease after neoadjuvant chemotherapy predicts an increased risk of lymphedema in nodepositive breast cancer patients. Ann Surg Oncol. 2013;20:2835-2841. doi: 10.1245/s 10434-012-2828-y.

24. Swaroop MN, Ferguson CM, Horick NK, Skolny MN, Miller CL, Jammallo LS, Brunelle CL, O'Toole JA, Isakoff SJ, Specht MC, Taghian AG. Impact of adjuvant taxane-based chemotherapy on development of breast cancer-related lymphedema: results from a large prospective cohort. Breast Cancer Res Treat. 2015;151:393-403. doi: 10.1007/s10549-015-3408-1.

25. Warren LE, Miller CL, Horick N, Skolny MN, Jammallo LS, Sadek BT, Shenouda MN, O'Toole JA, MacDonald SM, Specht MC, Taghian AG. The impact of radiation therapy on the risk of lymphedema after treatment for breast cancer: a prospective cohort study. Int J Radiat Oncol Biol Phys. 2014;88:565-571. doi: 10.1016/j.ijrobp.2013.11.232.

26. Rutkowski JM, Moya M, Johannes J, Goldman J, Swartz MA. Secondary lymphedema in the mouse tail: lymphatic hyperplasia, VEGF-C upregulation, and the protective role of MMP-9. Microvasc Res. 2006;72:161-171. doi: 10.1016/j.mvr.2006.05.009.

27. Karkkainen MJ, Saaristo A, Jussila L, Karila KA, Lawrence EC, Pajusola K, Bueler H, Eichmann A, Kauppinen R, Kettunen MI, Yla-Herttuala S, Finegold DN, Ferrell RE, Alitalo K. A model for gene therapy of human hereditary lymphedema. Proc Natl Acad Sci USA. 2001;98:12677-12682.

28. Daily K, Patel VR, Rigor P, Xie X, Baldi P. MotifMap: integrative genome-wide maps of regulatory motif sites for model species. $B M C$ Bioinformatics. 2011;12:495. doi: 10.1186/1471-2105-12-495.

29. Rosenbloom KR, Armstrong J, Barber GP, et al. The UCSC Genome Browser database: 2015 update. Nucleic Acids Res. 2015;43(Database issue):D670-D681. doi: 10.1093/nar/gku1177.

30. Prats AC, Van den Berghe L, Rayssac A, Ainaoui N, Morfoisse F, Pujol F, Legonidec S, Bikfalvi A, Prats H, Pyronnet S, Garmy-Susini B. CXCL4L1fibstatin cooperation inhibits tumor angiogenesis, lymphangiogenesis and metastasis. Microvasc Res. 2013;89:25-33. doi: 10.1016/j.mvr.2013.05.005.

31. Campbell L, Emmerson E, Williams H, Saville CR, Krust A, Chambon P, Mace KA, Hardman MJ. Estrogen receptor-alpha promotes alternative macrophage activation during cutaneous repair. J Invest Dermatol. 2014;134:2447-2457. doi: 10.1038/jid.2014.175.

32. Ghanta S, Cuzzone DA, Torrisi JS, Albano NJ, Joseph WJ, Savetsky IL, Gardenier JC, Chang D, Zampell JC, Mehrara BJ. Regulation of inflammation and fibrosis by macrophages in lymphedema. Am J Physiol Heart Circ Physiol. 2015;308:H1065-H1077.

33. Billon-Gales A, Fontaine C, Douin-Echinard V, Delpy L, Berges H, Calippe B, Lenfant F, Laurell H, Guery JC, Gourdy P, Arnal JF. Endothelial estrogen receptor-alpha plays a crucial role in the atheroprotective action of 17beta-estradiol in low-density lipoprotein receptor-deficient mice. Circulation. 2009;120:2567-2576.

34. Garmy-Susini B, Avraamides CJ, Schmid MC, Foubert P, Ellies LG, Barnes L, Feral C, Papayannopoulou T, Lowy A, Blair SL, Cheresh D, Ginsberg M, Varner JA. Integrin alpha4beta1 signaling is required for lymphangiogenesis and tumor metastasis. Cancer Res. 2010;70:3042-3051. doi: 10.1158/0008-5472.CAN-09-3761.

35. Zheng W, Aspelund A, Alitalo K. Lymphangiogenic factors, mechanisms, and applications. J Clin Invest. 2014;124:878-887. doi: 10.1172/JCI71603.

36. Evans MJ, Harris HA, Miller CP, Karathanasis SK, Adelman SJ. Estrogen receptors alpha and beta have similar activities in multiple endothelial cell pathways. Endocrinology. 2002;143:3785-3795. doi: 10.1210/en.2002-220356.

37. Röck K, Meusch M, Fuchs N, Tigges J, Zipper P, Fritsche E, Krutmann J, Homey B, Reifenberger J, Fischer JW. Estradiol protects dermal hyaluronan/versican matrix during photoaging by release of epidermal growth factor from keratinocytes. J Biol Chem. 2012;287:20056-20069. doi: 10.1074/jbc.M112.353151.

38. Ji RC. Lymphatic endothelial cells, lymphangiogenesis, and extracellular matrix. Lymphat Res Biol. 2006;4:83-100. doi: 10.1089/lrb.2006.4.83.

39. Hervé MA, Meduri G, Petit FG, Domet TS, Lazennec G, Mourah S, Perrot-Applanat M. Regulation of the vascular endothelial growth factor (VEGF) receptor Flk-1/KDR by estradiol through VEGF in uterus. J Endocrinol. 2006;188:91-99. doi: 10.1677/joe.1.06184.

40. Garmy-Susini B, Delmas E, Gourdy P, Zhou M, Bossard C, Bugler B, Bayard F, Krust A, Prats AC, Doetschman T, Prats H, Arnal JF. Role of fibroblast growth factor-2 isoforms in the effect of estradiol on endothelial cell migration and proliferation. Circ Res. 2004;94:1301-1309. doi: 10.1161/01.RES.0000127719.13255.81.

41. Arnal JF, Gourdy P, Garmy-Susini B, Delmas E, Bayard F. [Usefulness of experimental models to understand the vascular effects of estrogens]. Med Sci (Paris). 2003;19:1226-1232. doi: 10.1051/medsci/200319121226.

42. Dietze EC, Troch MM, Bean GR, Heffner JB, Bowie ML, Rosenberg P, Ratliff B, Seewaldt VL. Tamoxifen and tamoxifen ethyl bromide induce apoptosis in acutely damaged mammary epithelial cells through modulation of AKT activity. Oncogene. 2004;23:3851-3862. doi: 10.1038/sj.onc. 1207480 .

- Estrogens play a crucial role in lymphatic vessel function.

\section{Highlights}

- Estrogens protect from lymphedema through its receptor ER (estrogen receptor)- $\alpha$.

- Chronic long-term delivery of tamoxifen has a deleterious impact on lymphatic vessels.

- Tamoxifen affects both lymphatic endothelial cell gene expression and microenvironment. 